\title{
Neuroendocrine Hepatic Tumors: Summary of Patient Selection, Response and Toxicity of Radioembolization in 281 Patients
}

\section{Lowell Anthony}

MD, FACP, New Orleans, LA, USA

\begin{abstract}
Debulking neuroendocrine hepatic metastases is commonplace as both symptoms and disease are better controlled. The challenge in clinical decision making includes patient selection, timing and procedure. Extirpation, radiofrequency ablation, hepatic artery chemoembolization, bland embolization and radioembolization are techniques widely available in the U.S. For patients undergoing intrahepatic therapies, procedure selection is based not only on disease bulk but also on disease location. From 8 published studies, the outcomes of 281 patients who underwent radioembolization were reviewed. Symptomatic improvement occurs within 3 months in approximately half the patients. Partial biochemical responses ( $>50 \%$ reduction from baseline) using chromogranin A occur in two thirds of subjects as 2 centers have observed. Disease control (complete + partial + stable responses) is reported in $50-100 \%$ of patients. The median time to progression is 11.1 months in one report. Six centers report a median survival ranging from 14 to 70 months. One, 2 and 3 year survival ranges from 2 reports are $86-100 \%, 57-58 \%$ and 47-57\%, respectively.

As more choices become available in controlling neuroendocrine disease, optimally combining debulking procedures such as radioembolization with systemic therapy is challenging. Using infusional 5-FU with radioembolization can be done safely but added benefit remains uncertain. Prior hepatic artery chemoembolization may not be a contraindication to radioembolization. Future trials are needed to guide the practitioner in using radiation sensitizers with radioembolization.
\end{abstract}

\section{Introduction}

Neuroendocrine tumors (NETs) are increasing in incidence and are the second most prevalent malignancy of the gastrointestinal tract [1]. These tumors comprise a heterogeneous group that involves every organ system and ranges from the benign to the most aggressive. Common clinical presentations include misdiagnoses and delay in diagnosis that result in the majority of patients presenting with either locally advanced or metastatic disease. As treatment options such as radioembolization, peptide-receptor radiotherapy and targeted therapies are increasing, survival is improving with single-institutional outcomes significantly better than population-based studies and multi-disciplinary care necessary $[2,3]$.

A common cause of death in patients with NETs is liver failure due to hepatic replacement by tumor [4]. As liver metastases are a poor prognostic feature, treatment goals include not only controlling

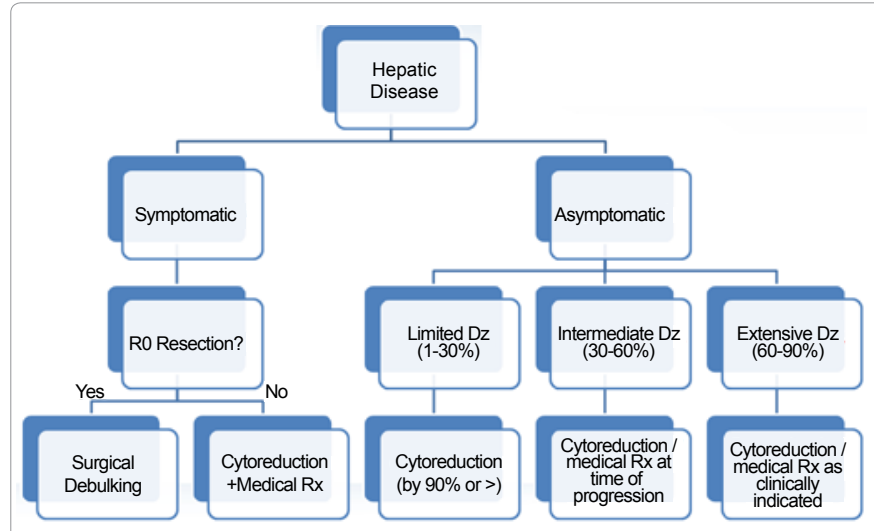

Figure 1: Management of hepatic neuroendocrine metastases. Cytoreduction refers to resection, radiofrequency ablation, hepatic artery radioembolization, chemoembolization or bland embolization. symptoms but also the disease while improving the quality of life. For patients with either well-differentiated or intermediate-grade neoplasms, debulking with either cytoreductive surgery, hepatic embolization or radiofrequency ablation offer the potential for meaningful improvement in symptom palliation by reducing hormonal levels and overall tumor burden (see Figure 1).

For patients that are non-surgical candidates, liver regional therapy options include hepatic embolization, chemoembolization, hepatic perfusion and brachytherapy [5]. These regional arterial therapies are administered through angiographic catheters and delivered into a segmental, lobar or whole liver distribution. Particle embolization with or without chemotherapy has become standard therapy for patients with extensive liver involvement. While data suggest that the addition of intra-arterial cytotoxic chemotherapy improves outcome for patients with pancreatic NETs, there are conflicting data for patients with midgut NETs as the target populations and techniques are too heterogeneous and inconsistent, respectively [6]. The post-embolization syndrome (malaise, fever, pain and nausea) that predictably occurs following a bland or chemoembolization, requires a short hospitalization stay for support (intravenous fluids, antibiotics, antiemetics and analgesics).

Radioembolization is a form of brachytherapy that uses the hepatic artery as a conduit to selectively deliver the $\beta$-emittery ttrium-90.

*Corresponding author: Lowell Anthony, MD, FACP, New Orleans, LA, USA, E-mail:LAntho@Isuhsc.edu

Received April 26, 2011; Accepted May 26, 2011; Published June 15, 2011

Citation: Anthony L (2011) Neuroendocrine Hepatic Tumors: Summary of Patient Selection, Response and Toxicity of Radioembolization in 281 Patients. J Nucl Med Radiat Ther 2:104. doi:10.4172/2155-9619.1000104

Copyright: @ 2011 Anthony L. This is an open-access article distributed under the terms of the Creative Commons Attribution License, which permits unrestricted use, distribution, and reproduction in any medium, provided the original author and source are credited. 
Citation: Anthony L (2011) Neuroendocrine Hepatic Tumors: Summary of Patient Selection, Response and Toxicity of Radioembolization in 281 Patients. J Nucl Med Radiat Ther 2:104. doi:10.4172/2155-9619.1000104

Page 2 of 4

\begin{tabular}{|c|c|c|c|c|c|c|c|c|c|c|}
\hline Author & $\mathbf{N}$ & $\begin{array}{l}\mathbf{R x} \\
(\mathrm{N})\end{array}$ & Symptomatic Response & $\begin{array}{l}\text { Biochemical } \\
\text { Response, CGA }\end{array}$ & \multicolumn{3}{|c|}{$\begin{array}{l}\text { Disease Control } \\
\text { (CR / PR / SD) }\end{array}$} & $\begin{array}{l}\text { Median } \\
\text { TTP, mos }\end{array}$ & $\begin{array}{l}\text { Median } \\
\text { Survival, } \\
\text { mos (range) }\end{array}$ & Comments \\
\hline \multirow{2}{*}{$\begin{array}{l}\text { Cao } \\
2010\end{array}$} & \multirow{2}{*}{$\begin{array}{l}58 \\
\text { (51 evaluable) } \\
\text { (42 carcinoid) }\end{array}$} & \multirow{2}{*}{ SS } & \multirow{2}{*}{ NR } & \multirow{2}{*}{ NR } & \multicolumn{3}{|c|}{$58 \%(\mathrm{ITT})$} & \multirow{2}{*}{ NR } & \multirow{2}{*}{$\begin{array}{l}36 \\
(1-61)\end{array}$} & \multirow{2}{*}{$\begin{array}{l}1,2,3 \text { yr OS: } \\
86 \% / 58 \% / 47 \%\end{array}$} \\
\hline & & & & & $10 \%$ & $24 \%$ & $24 \%$ & & & \\
\hline \multirow{2}{*}{$\begin{array}{l}\text { Gulec } \\
2007\end{array}$} & \multirow{2}{*}{10} & \multirow{2}{*}{ SS } & \multirow{2}{*}{ NR } & \multirow{2}{*}{ NR } & \multicolumn{3}{|l|}{$100 \%$} & \multirow{2}{*}{ NR } & \multirow{2}{*}{ NR } & \\
\hline & & & & & NR & NR & NR & & & \\
\hline \multirow{2}{*}{$\begin{array}{l}\text { Kalinowski } \\
2009\end{array}$} & \multirow[t]{2}{*}{9} & \multirow[t]{2}{*}{ SS } & \multirow{2}{*}{$\begin{array}{l}\text { Increase QLQ-C30 \& } \\
\text { LMC21 at } 3 \text { mos \& returns } \\
\text { to baseline at } 12 \text { mos }\end{array}$} & \multirow[t]{2}{*}{$66 \%$} & \multicolumn{3}{|l|}{$100 \%$} & \multirow[t]{2}{*}{11.1} & \multirow[t]{2}{*}{ NR } & \multirow{2}{*}{$\begin{array}{l}1,2,3 \text { yr OS: } \\
100 \% / 57 \% / 57 \% \\
\text { Acute \& late AEs: very } \\
\text { low }\end{array}$} \\
\hline & & & & & $0 \%$ & $67 \%$ & $33 \%$ & & & \\
\hline \multirow{2}{*}{$\begin{array}{l}\text { Kennedy+ } \\
2008\end{array}$} & \multirow{2}{*}{148} & \multirow{2}{*}{ SS } & \multirow{2}{*}{ NR } & \multirow{2}{*}{ NR } & \multicolumn{3}{|c|}{$85.9 \%$} & \multirow{2}{*}{ NR } & \multirow{2}{*}{70} & \\
\hline & & & & & $2.7 \%$ & $60.5 \%$ & $22.7 \%$ & & & \\
\hline & & & & $66 \%$ PR & $50 \%$ & & & & & \\
\hline $\begin{array}{l}\text { King* } \\
2008\end{array}$ & 34 & $\begin{array}{l}5 \mathrm{~S} \\
+ \\
5-\mathrm{FU}\end{array}$ & 6 mos: $50 \%$ & $\begin{array}{l}\text { 60\% PR } \\
\text { Pancreas }\end{array}$ & $18 \%$ & $32 \%$ & & NR & 29.4 & $\begin{array}{l}1 \text { early death from liver } \\
\text { dysfunction }\end{array}$ \\
\hline Murthy & & & & & $62.5 \%$ & & & & & Radioembo safe with \\
\hline 2008 & 8 & SS & NR & NR & & $12.5 \%$ & $50 \%$ & NR & $(3-15)$ & prior HA embolization \\
\hline Rhee+ & & $\begin{array}{l}\text { SS } \\
(20)\end{array}$ & & & $\begin{array}{l}75 \% \mathrm{~S} \\
55 \% \mathrm{~T}\end{array}$ & & & & $28 \mathrm{SS}$ & Compared resin (SS) vs \\
\hline 2008 & 42 & $\begin{array}{l}\text { TS } \\
(22)\end{array}$ & NR & $\mathrm{NR}$ & & $\begin{array}{l}40 \% \text { SS } \\
32 \% \text { TS }\end{array}$ & $\begin{array}{l}35 \% \text { SS } \\
23 \% \text { TS }\end{array}$ & $\mathrm{NR}$ & & glass (TS) \\
\hline Saxena* & $\begin{array}{l}48 \\
\text { (16 small bowel: }\end{array}$ & SS & NR & NR & $78 \%$ & & & NR & & Significant inc in alkaline \\
\hline 2010 & 16 pancreas) & & & & $15 \%$ & $40 \%$ & $23 \%$ & 年 & $(5-63)$ & phosphatase over 6 mos \\
\hline
\end{tabular}

*Updated report from the senior author +Overlap of institutions / authors

Abbreviations: $\mathrm{Rx}=$ treatment; $\mathrm{SS}=\mathrm{SirSpheres;} \mathrm{TS}=$ TheraSpheres; $\mathrm{CGA}=$ chromogranin $\mathrm{A} ; \mathrm{NR}=$ not reported; OS = overall survival; inc = increased; $\mathrm{CR}=$ complete response; $\mathrm{PR}=$ partial response; $\mathrm{SD}=$ stable disease; Biochemical $\mathrm{PR}=50 \%$ reduction from baseline; TTP $=$ time to progression; mos = months; $\mathrm{HA}=$ hepatic artery; ITT=intent to treat; Radioembo=radioembolization

Table 1: Summary of the Radioembolization Experience in 281 Metastatic NET Patients.

This type of radiation is effective and well tolerated in cancer patients with hepatic metastases $[7,8]$. Since stasis of blood flow is not a goal of radioembolization, patients do not generally require hospitalization for management of symptoms and complications. In the absence of prospective multi-center head-to-head comparator trials assessing the efficacy and safety of embolization procedures vs regional brachytherapy, deciding between the two procedures is determined more by individual patient characteristics and/or the experience of the managing physician/team.

Therapies that anatomically or physiologically disrupt blood vessels such as embolization/chemoembolization or VEGF inhibitors may affect the efficacy of subsequent agents intra-arterially delivered. Sequencing bland- or chemoembolization with radioembolization has been reported [9]. As one intrahepatic therapy may influence another, there are no studies to guide the optimal sequencing of these treatments. The success of intra-hepatic brachytherapy depends upon, at least in part, the availability and integrity of the hepatic vasculature. Additional studies are needed to guide these clinical decisions. The aim of this review is to discuss patient selection factors and to evaluate the efficacy and toxicity of regionally directed intra-hepatic radioactive therapy. To identify pertinent peer-reviewed references through 2010, Medline was searched using the following terms: "therapeutic , embolization", "Yttrium radioisotopes", "neuroendocrine tumor", "carcinoid". Eight references were identified and form the basis for this review [10$13,9,14-16]$.

\section{Patient selection}

Stage IV neuroendocrine tumor patients present with variable degrees of hepatic involvement that can be focal or diffuse. For nonsecretory tumors, signs and symptoms of hepatomegaly can be, at least in part, that which brings the patient to seek medical attention. Patients considered for radioembolization include those with a Karnofsky Performance Status $\geq 60 \%$, hepatic dominant metastatic and unresectable metastatic disease with an expected survival of at least 3 months [17]. Symptomatic syndromic patients on depot somatostatin analogs may benefit from supplemental intravenous or subcutaneous formulation to lower the risk of a prolonged hypotensive or carcinoid crisis. For patients whose symptoms are well-controlled or absent, the prophylactic use of immediate release octreotide to supplement the depot formulation is unclear.

Radioembolization is contraindicated if (1) an uncorrectable and clinically significant ( $\geq 30$ Gy radiation exposure to extra-hepatic sites) extra-hepatic shunt is present on the pretreatment ${ }^{99 \mathrm{~m}} \mathrm{Tc}$ macroaggregated albumin (MAA) scan (2) extensive hepatic tumor burden with limited hepatic reserve (3) elevated total bilirubin $(>2.0 \mathrm{mg} / \mathrm{dl})$ (4) portal vein occlusion in the absence of a selective or superselective angiographic technique feasibility [17]. Combining radioembolization with cytotoxic chemotherapy, $[13,18-20]$ targeted therapies and other forms of radiation therapy (external beam or infusional therapy with I-131 MIBG [21] or Lu-177 tetraazacyclododecane tetraacetic acid-d-Phe(1)-Tyr(3)-octreotide (DOTATOC)is unclear and are the topics for clinical investigations not only in NETs but also in other malignancies. Prior external beam radiotherapy may be considered a relative contraindication but depends upon the dose delivered and the radiation port [17]

\section{Response assessments}

Objective evidence of response is more likely to be either radiographic responses or survival analysis using Kaplan-Meier statistics to calculate time to progression (TTP) and median overall 
survival (OS). Survival percentages at fixed time points such as 1,2 and 3 years may also be reported (see Table 1).

Symptomatic: Improvement in syndrome or symptom control is not well documented as many of these reports are retrospective and performed without extra-mural funding. The prospective single center trials are more likely to have a small patient number secondary to the rarity of the condition. An increase in quality of life occurred at 3 months post therapy and gradually returned to baseline one year later [11]. Another study reported symptom improvement in approximately half the patients at 3 and 6 months post therapy [13].

Biochemical: Biochemical markers are infrequently monitored as part of routine care in many centers. Obtaining baseline biomarker levels is challenging even with extra-mural support and/or funding. Another variable is the heterogeneity in the patient populations with respect to primary site and which biochemical marker is over secreted. The scarcity of these data (see Table 1) as surrogate endpoints diminishes theirrobustness. One study ( $\mathrm{N}=9$ small bowel NETs) did demonstrate a $60-70 \%$ partial response rate using chromogranin A levels at 3 and 6 months with similar results confirmed by another group ( $N=9$ with 4 small bowel NETs) $[11,13]$

Radiographic: Disease control (complete response + partial response + stable disease) is a meaningful measure if progressive disease patients were selected and/or the procedure is relatively non-toxic. The mean (+/- S.E., range) disease control rate of the 281 patients in the literature is $75 \%(+/-6 \%, 50-100 \%)$ with some reports of complete responses that are more likely to occur in patients with low bulk disease (see Table 1).

Survival: The variability in survival endpoint reporting makes it difficult to compare outcomes across centers. The median time to progression (TTP) reported by only one center was 11.1 months [11]. The "median" median overall survival (OS) from six centers was 29.4 months (+/- 6.7 mos, S.E.) (see Table 1). The respective 1, 2 and 3 year survival statistics from 2 centers were: $86 \%, 58 \%, 47 \%$ and $100 \%, 57 \%$, $57 \%[10,11]$

\section{Toxicity}

Significant toxicity (CTCae 3.0 grade $3-4$ ) following ${ }^{90} \mathrm{Y}$-microsphere treatment is mostly fatigue $(6.5 \%)$, nausea $(3.2 \%)$ and pain $(2.7 \%)$ with 1 report of ascites but $66 \%$ of patients reported no severe side effects in the largest multi-center retrospective report [12]. These side effects are similar to those observed from radioembolization in other disease states [22]. Comparing side effects between radioembolization and other hepatic artery treatments such as chemoembolization, favors radioembolization for patients with primary liver cancer [23]. Extrahepatic complications occur but are infrequent based on the selection and preparation of patients [24-30,22,31,32,12,33-35]. Hepatic abscess have also been reported in NETs [36]. Techniques are described to further minimize complications [37-39].

\section{Conclusions}

Debulking liver disease in NETs patients is commonly done either for symptom control or at the time of local progression. Radioembolization preferentially delivers high radiation doses to hepatic NET metastases and is effective, safe and comparable to other local therapies in this patient population. Though extrahepatic complication are possible; the benefits outweigh the risks of adverse events from further disease progression. Improvement in symptoms can be expected within 3 months of the procedure with durability for another 6-9 months. Biochemical markers are more likely to decrease by $50 \%$ in the first 90 day period in the majority of patients and not progress over the next 6 months. Disease control is to be expected in $75 \%$ of subjects and a $1-y r$ survival rate of $85-100 \%$. Median overall survival is approximately 2.5 years and reflects the relative advanced patient receiving radioembolization as salvage therapy.

Further progress is necessary in improving outcomes. Future efforts in identifying additive or synergistic combination therapies with radioembolization is on the immediate forefront not only for NET patients but in hepatocellular cancer, colorectal cancer and other malignancies involving the liver. With its safety and efficacy wellestablished in NET patients, using radioembolization earlier in disease management when complete radiographic responses occur, may allow further improvements in overall survival.

\section{References}

1. Yao JC, Hasan M, Phan A, Dagohoy C, Leary C, et al. (2008) One hundred years after "carcinoid": epidemiology of and prognostic factors for neuroendocrine tumors in 35,825 cases in the United States. J Clin Oncol 26: 3063-3072.

2. Strosberg J, Halfdanarson T (2011) Survival analyses of pancreatic neuroendocrine tumors: Contrasting institutional databases with populationbased studies. J Clin Oncol 129.

3. Liu DM, Kennedy A, Turner D, Rose SC, Kee ST, et al. (2009) Minimally invasive techniques in management of hepatic neuroendocrine metastatic disease. Am J Clin Oncol 32: 200-215

4. Mignon M (2000) Natural history of neuroendocrine enteropancreatic tumors Digestion 1: 51-58

5. Landry CS, McMasters KM, Scoggins CR (2007) The evolution of the management of regional lymph nodes in melanoma. J Surg Oncol 96: 316-321.

6. Gupta S, Johnson MM, Murthy R, Ahrar K, Wallace MJ, et al. (2005) Hepatic arterial embolization and chemoembolization for the treatment of patients with metastatic neuroendocrine tumors: variables affecting response rates and survival. Cancer 104: 1590-1602.

7. Kennedy AS, Salem R (2010) Radioembolization (yttrium-90 microspheres) for primary and metastatic hepatic malignancies. Cancer J 16: 163-175.

8. Van De Wiele C, Defreyne L, Peeters M, Lambert B (2009) Yttrium-90 labelled resin microspheres for treatment of primary and secondary malignant liver tumors. Q J Nucl Med Mol Imaging 53: 317-324.

9. Murthy R, Kamat P, Nunez R, Madoff DC, Gupta S, et al. (2008) Yttrium-90 microsphere radioembolotherapy of hepatic metastatic neuroendocrine carcinomas after hepatic arterial embolization. J Vasc Interv Radiol 19: 145151.

10. Cao CQ, Yan TD, Bester L, Liauw W, Morris DL (2010) Radioembolization with yttrium microspheres for neuroendocrine tumour liver metastases. $\mathrm{Br} \mathrm{J}$ Surg 97: $537-543$

11. Kalinowski M, Dressler M, Konig A, El-Sheik M, Rinke A, et al. (2009) Selective internal radiotherapy with Yttrium-90 microspheres for hepatic metastatic neuroendocrine tumors: a prospective single center study. Digestion 79: 137 142

12. Kennedy AS, Dezarn WA, McNeillie P, Coldwell D, Nutting C, et al. (2008) Radioembolization for unresectable neuroendocrine hepatic metastases using resin 90Y-microspheres: early results in 148 patients. Am J Clin Oncol 31: 271 279 .

13. King J, Quinn R, Glenn DM, Janssen J, Tong D, et al. (2008) Radioembolization with selective internal radiation microspheres for neuroendocrine liver metastases. Cancer 113: 921-929.

14. Rhee TK, Lewandowski RJ, Liu DM, Mulcahy MF, Takahashi G, et al. (2008) 90Y Radioembolization for metastatic neuroendocrine liver tumors: preliminary results from a multi-institutional experience. Ann Surg 247: 1029-1035.

15. Saxena A, Chua TC, Bester L, Kokandi A, Morris DL (2010) Factors predicting response and survival after yttrium- 90 radioembolization of unresectable neuroendocrine tumor liver metastases: a critical appraisal of 48 cases. Ann Surg 251: 910-916 
Citation: Anthony L (2011) Neuroendocrine Hepatic Tumors: Summary of Patient Selection, Response and Toxicity of Radioembolization in 281 Patients. J Nucl Med Radiat Ther 2:104. doi:10.4172/2155-9619.1000104

16. Gulec SA, Mesoloras G, Dezarn WA, McNeillie P, Kennedy AS (2007) Safety and efficacy of $\mathrm{Y}-90$ microsphere treatment in patients with primary and metastatic liver cancer: the tumor selectivity of the treatment as a function of tumor to liver flow ratio. $\mathrm{J}$ Transl Med 5: 15.

17. Kennedy A, Nag S, Salem R, Murthy R, McEwan AJ, et al. (2007) Recommendations for radioembolization of hepatic malignancies using yttrium-90 microsphere brachytherapy: a consensus panel report from the radioembolization brachytherapy oncology consortium. Int J Radiat Oncol Biol Phys 68: 13-23.

18. Hendlisz A, Van den Eynde M, Peeters M, Maleux G, Lambert B, et al. (2010) Phase III trial comparing protracted intravenous fluorouracil infusion alone or with yttrium-90 resin microspheres radioembolization for liver-limited metastatic colorectal cancer refractory to standard chemotherapy. J Clin Oncol 28: 3687 3694

19. Cosimelli M, Golfieri R, Cagol PP, Carpanese L, Sciuto R, et al. (2010) Multi-centre phase II clinical trial of yttrium-90 resin microspheres alone in unresectable, chemotherapy refractory colorectal liver metastases. $\mathrm{Br} \mathrm{J}$ Cancer 103: 324-331.

20. Nicolay NH, Berry DP, Sharma RA, Medscape et al. (2009) Liver metastases from colorectal cancer: radioembolization with systemic therapy. Nat Rev Clin Oncol 6: 687-697.

21. McStay MK, Maudgil D, Williams M, Tibballs JM, Watkinson AF, et al (2005) Large-volume liver metastases from neuroendocrine tumors: hepatic intraarterial 90Y-DOTA-lanreotide as effective palliative therapy. Radiology 237 718-726.

22. Kennedy AS, McNeillie P, Dezarn WA, Nutting C, Sangro B, et al. (2009) Treatment parameters and outcome in 680 treatments of internal radiation with resin 90Y-microspheres for unresectable hepatic tumors. Int J Radiat Oncol Biol Phys 74: 1494-1500.

23. Salem R, Lewandowski RJ, Kulik L, Wang E, Riaz A, et al. (2011) Radioembolization results in longer time-to-progression and reduced toxicity compared with chemoembolization in patients with hepatocellular carcinoma. Gastroenterology 140: 497-507.

24. Nair J, Liu C, Caridi J, Zlotecki R, George TJ Jr (2010) Gastroduodena ulcerations as a delayed complication of hepatic metastasis radioembolization. J Clin Oncology 28: e735-e736.

25. Hoffman MA, Rubin JI, Vinceguerra VP, Nowakowski FS, Warner RR (2008) Severe coagulopathy after $90 \mathrm{Y}$ microsphere administration: resemblance to the Kasabach-Merritt syndrome. J Vasc Interv Radiol 19: 1099-1102.

26. Carretero C, Munoz-Navas M, Betes M, Angos R, Subtil JC, et al. (2007) Gastroduodenal injury after radioembolization of hepatic tumors. Am J Gastroenterol 102: 1216-1220.
27. Patel NM, Yuan J, David J (2010) Cholecystoduodenal fistula after yttrium-90 radioembolization. J Clin Gastroenterol 44: 594-595.

28. Naymagon S, Warner RR, Patel K, Harpaz N, Machac J, et al. (2010) Gastroduodenal ulceration associated with radioembolization for the treatment of hepatic tumors: an institutional experience and review of the literature. Dig Dis Sci 55: $2450-2458$

29. Gaba RC, Riaz A, Lewandowski RJ et al. (2010) Safety of yttrium-90 microsphere radioembolization in patients with biliary obstruction. J Vasc Interv Radiol 21: 1213-1218.

30. Bilbao Jl, Garrastachu P, Herraiz MJ, Rodríguez M, Iñarrairaegui $M$, et al (2010) Safety and efficacy assessment of flow redistribution by occlusion of intrahepatic vessels prior to radioembolization in the treatment of liver tumors. Cardiovasc Intervent Radiol 33: 523-531.

31. Salem R, Parikh P, Atassi B, Lewandowski RJ, Ryu RK, et al. (2008) Incidence of radiation pneumonitis after hepatic intra-arterial radiotherapy with yttrium-90 microspheres assuming uniform lung distribution. Am J Clin Oncol 31: 431-438.

32. McCarthy P, Kennedy A, Dawson P, Allison D et al. (1991) Pulmonary embolus as a complication of therapeutic peripheral arteriovenous malformation embolization. Br J Radiol 64: 177-178.

33. Crowder CD, Grabowski C, Inampudi S, Sielaff T, Sherman CA, et al. (2009) Selective internal radiation therapy-induced extrahepatic injury: an emerging cause of iatrogenic organ damage. Am J Surg Pathol 33: 963-975.

34. Salem R, Lewandowski RJ, Kulik L, Wang E, Riaz A, et al. (2011) Radioembolization results in longer time-to-progression and reduced toxicity compared with chemoembolization in patients with hepatocellular carcinoma. Gastroenterology 140: 497-507.

35. Hilgard P, Hamami M, Fouly AE, Scherag A, Müller S, et al. (2010) Radioembolization with yttrium- 90 glass microspheres in hepatocellular carcinoma: European experience on safety and long-term survival. Hepatology 52: $1741-1749$.

36. Mascarenhas NB, Mulcahy MF, Lewandowski RJ, Salem R, Ryu RK (2010) Hepatic abscess after yttrium-90 radioembolization for islet-cell tumor hepatic metastasis. Cardiovasc Intervent Radiol 33: 650-653.

37. Maleux G, Heye S, Vaninbroukx J, Deroose C et al. (2010) Angiographic considerations in patients undergoing liver-directed radioembolization with $90 \mathrm{Y}$ microspheres. Acta Gastroenterol Belg 73: 489-496.

38. Riaz A, Gates VL, Atassi B, Lewandowski RJ, Mulcahy MF et al. (2011) Radiation segmentectomy: a novel approach to increase safety and efficacy of radioembolization. Int J Radiat Oncol Biol Phys 79: 163-171.

39. Cosin O, Bilbao Jl, Alvarez S, de Luis E, Alonso A, et al. (2007) Right gastric artery embolization prior to treatment with yttrium- 90 microspheres. Cardiovasc Intervent Radiol 30: 98-103. 